Orbis Tertius, vol. XXV, $\mathrm{n}^{\circ}$ 32, e179, noviembre 2020-abril 2021. ISSN 1851-7811

Universidad Nacional de La Plata

Facultad de Humanidades y Ciencias de la Educación

Centro de Estudios de Teoría y Crítica Literaria

\title{
Manuel Puig. De amicitia
}

\section{Manuel Puig: De amicitia}

\author{
Jorge Panesi \\ jorgepanesi@me.com \\ Universidad de Buenos Aires - Universidad Nacional \\ de La Plata, Argentina
}

Cita sugerida: Panesi, J. (2020). Manuel Puig. De amicitia. Orbis Tertius, 25(30), e179.

https://doi.org/10.24215/18517811e179

\begin{abstract}
Resumen: En el presente trabajo Jorge Panesi, motivado por el recuerdo plasmado en una dedicatoria conservada en la biblioteca personal de Manuel Puig, evoca el recuerdo de una escritura que conecta a la literatura con la tarea de crítico por medio de las deudas y los diálogos que se tejen alrededor del afecto, de la práctica intelectual y de la amistad. En su reflexión, Panesi regresa a su propio texto para reflexionar allí acerca de los lenguajes, las tradiciones y los traumas de la historia argentina que convivieron y jalonaron la escritura de su trabajo y que perviven silenciosamente en el andamiaje argumentativo de aquella pionera y cuidadosa lectura de la narrativa de Puig.
\end{abstract}

Palabras clave: Manuel Puig, Crítica literaria, Amistad, Literatura argentina.

\begin{abstract}
In this work Jorge Panesi, motivated by the memory embodied in a dedication preserved in the personal library of Manuel Puig, evokes the memory of a writing that connects literature with the task of critic through the debts and dialogues that are woven around affection, intellectual practice and friendship. In his reflection, Panesi returns to his own text to reflect there on languages, the traditions and traumas of the Argentine history that coexisted and marked the writing of his work and that remain silently in the argumentative scaffolding of that pioneer and careful reading of the narrative of Puig.
\end{abstract}

Keywords: Manuel Puig, Literary Criticism, Friendship, Argentine literature.

A pesar de que siempre me maravilló el ansia de Manuel Puig por conservar los distintos estadios de su trabajo (verdadero tesoro para los genetistas), no creía que fuese de su interés la amplia bibliografía crítica que se ocupó de sus novelas, y menos que mi artículo "Manuel Puig: las relaciones peligrosas" (Panesi, 1983) fuera merecedor de su afán archivero. Claro, mi admiración por sus novelas me hacía olvidar algo que también descuidé en ese trabajo: en Puig el acopio narcisista se ligaba (imagino ahora con dudosa certidumbre) con la actitud de las divas cinematográficas que guardan recortes de revistas para asegurarse de que su nombre, junto con su fama, permanecían fulgurantes y se elevaban en una suerte de estrellato. 


\section{FIGURA 1}

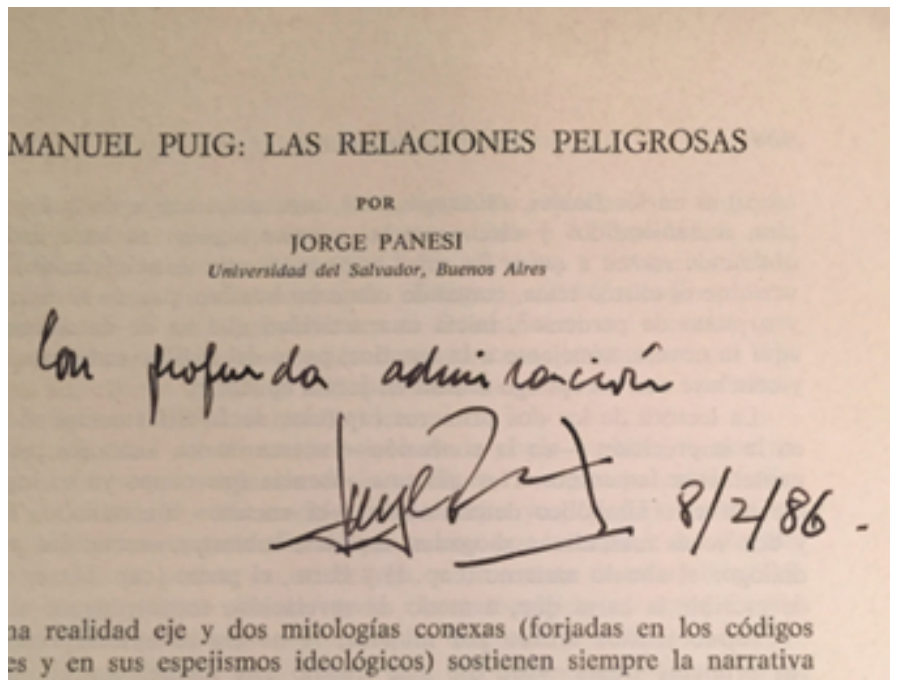

(Biblioteca Manuel Puig)

Lejos de las vanaglorias de esas actrices que Puig admiraba, el fulgor de la crítica es efímero, pasajero, enredado siempre con el olvido. Al saber que el equipo de Graciela Goldchluk había encontrado una separata de ese artículo mío aparecido en la Revista Iberoamericana de Pittsburgh (1983), no experimenté el regusto vanidoso de las divas retiradas al comprobar que su público no las ha olvidado. Nada de eso. Soy consciente de que los textos críticos envejecen tanto como las ideas o los prejuicios de la época que los acuna. Una profesora argentina cuya tesis doctoral dedicó a Puig, me dijo una vez: "a vos te tocó la época de Bajtín". Insidiosamente desnudaba una de las dos penurias de nuestro oficio: nuestros textos están doblemente amarrados, casi esclavizados, no solo por el indisociable vínculo con un tipo de literatura, con una época o corriente determinada o con un autor, sino que también son deudores de las ideas (o prejuicios) de las teorías (solo en apariencia menos efímeras y prejuiciosas) que circulan en el ámbito universitario y más allá de él. Segura y lamentablemente mi artículo debía mucho a Bajtín, aunque nunca fue un núcleo de mi enseñanza, ni tuviese mi aprecio intelectual: las ideas y posiciones literarias son escurridizas, se cuelan por todas partes, y salpican como la lluvia. Es más: he llegado a concordar con las investigaciones de Jean-Paul Bronckart y Christian Bota en Bajtin desenmascarado. Historia de un mentiroso, una estafa y un delirio colectivo(2013 [2011]), pero esta convicción, por supuesto, era inimaginable en 1983, cuando escribí el artículo.

Pero sí, es cierto: cuando ahora lo releo, con pánico, con condescendencia y con vergüenza por conocimientos que no tenía, advierto consternado que el párrafo final es una referencia a Mijaíl Bajtín:

Si, como vio Bajtín, la novela es el género dialógico por excelencia, si la novela se constituye a partir de un dialogo que es entrecruzamiento, las alianzas, mezclas y pugnas de la ideología, nadie, entonces en la literatura argentina actual, ejecutó mejor este despliegue de voces encontradas y desencontradas que Manuel Puig (Panesi, 1983, p. 917)

También es cierto, me digo resignado por mi participación entusiasta en la doxa académica, que Bajtín no cumple ninguna función en lo que es un típico "análisis de texto" a la manera formalista. Y me excuso a mí mismo porque en el artículo también se cita a Iuri Tinianov, mucho más cerca de mi pensamiento de entonces: "...la vida social entra en correlación con la literatura, ante todo, por su aspecto verbal" (2016, p. 134). Se me puede objetar que esta frase en absoluto está en contradicción con las ideas bajtinianas, a lo que yo respondería que mi adhesión de entonces (y también de ahora) estaba centrada en el formalismo ruso, casi una fidelidad, como en el caso de Ricardo Piglia, cuyas clases sobre Onetti llevan justicieramente un título de Víctor Schklovski: Teoría de la prosa(Piglia, 2019). Cito a Piglia porque mi trabajo lo citaba también a él, a propósito de La traición de Rita Hayworth. (1972 [1969]) Más que atravesado por Bajtín o por los formalistas, yo era deudor de las discusiones que se mantenían entonces en la crítica argentina. 
Particularmente "Manuel Puig: Las relaciones peligrosas" sigue o mimetiza un modo de análisis puesto en circulación por Josefina Ludmer (1971), modo que ella retrospectivamente llamó “análisis micrológico", vale decir una forma de lectura textual claramente inspirada en el estructuralismo.

Esta lectura tiene las ventajas y los inconvenientes de una concepción literaria subyacente, la creencia en cierta autonomía textual, en una lógica interior del texto que no es otra cosa que la autorreferencialidad. Ahora, al releerme, advierto el esfuerzo por congeniar esta concepción con otra que siempre estuvo entre mis inquietudes (que son las mismas que aparecen en las novelas de Puig): la relación de aquello que se narra con la política. Esfuerzo que seguramente aprendí tanto de Piglia como de Ludmer. Pero advierto en este instante que la costura que trata de unir esas dos concepciones (que no tendrían que ser antagónicas) no siempre disimula que se trata de un zurcido.

Más que Bajtin o el particular análisis microscópico o detallista, es la teoría psicoanalítica la que enmarca lo que dije sobre La traición de Rita Hayworth y las otras novelas de Puig, marco fácilmente comprobable en las citas a pie de página (Lacan, Moustapha Safouan, Guy Rosolato). Una marca de época que no solo impregna cierto tipo de crítica literaria como la mía, sino también la escritura de Puig. Todos leíamos psicoanálisis, todos nos aventurábamos en los jeroglíficos lacanianos. La cuestión es qué hacíamos con ellos. La clara huella (casi paródica) de esta manía lectora usada con estrictos fines narrativos la encontramos, como es obvio, en las notas marginales de El beso de la mujer araña. Lo extraño hubiese sido que Puig no hubiese tomado en cuenta o no hubiese usado las ideas que estaban presentes en las discusiones intelectuales de la época y que contribuían a darle a la cultura argentina de entonces unos brochazos coloridos, evidentes, característicos. Mi amigo Luis Gusmán siempre recuerda una observación que le hice hace mucho tiempo, y que creo es una característica de casi toda su escritura literaria: la separación tajante entre su actividad psicoanalítica y sus novelas o ensayos, como si quisiese preservar a la literatura de una invasión o de un contagio que hubiera contaminado inevitablemente una supuesta pureza esencial. Pero la suya es la excepción y no la regla que rige para un grupo de novelas y novelistas entre los que está Manuel Puig.

Por suerte para la narrativa de Puig, no escribí más sobre él, ni tampoco insistí en leerlo según el derrotero teórico de un Profesor de Teoría Literaria, es decir, como esos personajes en permanente angustia por probar todas las mercancías de los escaparates, porque la crítica universitaria, lo quiera o no, siempre está pendiente de lo que se usa o se deja de usar; no en vano Barthes, una de las estampas más consumadas del crítico literario en el siglo XX, escribió un Sistema de la moda. Estoy seguro de que esta conexión entre los críticos y la alta costura hubiera divertido mucho a Manuel Puig.

Especulaciones que se agregan a aristas más bien sentimentales. Ahora sé que ese artículo mío era fruto de la amistad. No de la amistad de Puig, porque no lo conocí. Le mandé unas líneas cuando lo estaba escribiendo, creo que para pedirle un consejo. Me respondió con otras breves líneas casi telegráficas y luego le envié la separata con una dedicatoria. Como un crítico que recién comenzaba yo era bastante candoroso, a pesar de que paralelamente enseñaba con convicción sobreactuada aquello de "la muerte del autor". Escribí sobre muchos de mis amigos, pero jamás he repetido esa bochornosa escena en que un crítico le pide consejos al autor sobre el que escribirá.

Era casi obligado que escribiese sobre un amigo de mis amigos de entonces: Enrique Pezzoni, Josefina Ludmer, Luis Gusmán. Todos ellos me contaban anécdotas, sucedidos, frases que tenían a Manuel Puig como héroe. "Las relaciones peligrosas", en verdad eran las relaciones amistosas a las que yo, sin saberlo, quería honrar. Ahora son imágenes, relatos que han perdido a su autor, producto, más bien, de un afectuoso sujeto colectivo: Puig en un taxi seduciendo al taxista, Puig sin una biblioteca identificable en su departamento de Río de Janeiro, Puig asistiendo a una clase de un amigo universitario en Estados Unidos, Puig consultando a una bruja o numeróloga que adivinaba el futuro...

De modo que escribir sobre Puig fue prolongar una amistad a la que yo asistía como un deslumbrado sicario, un recién venido a la tertulia donde se hablaba de un personaje ausente. Quizá de esa ausencia tan rotunda (hacía tiempo que Puig no vivía en el país) surgió el deseo de ser su amigo también, para no quedar afuera 
de la conversación. Escribir crítica a veces es el deseo insatisfecho por intimar con el autor. Una intimidad siempre prometida y siempre diferida.

Las amistades literarias, más allá de los efectivos lazos sentimentales, están mediadas, distanciadas tal vez, por el mismo rasgo que las constituye: la lectura y la escritura, los libros. Es lo que recientemente Luis Gusmán nos cuenta a propósito de su amistad con Manuel Puig: "Nos conocimos a través de los libros. Yo tenía una gran admiración por su primera novela, La traición de Rita Hayworth. Él por El frasquito" (2020).

Luis está convencido de que los libros son "una forma de la amistad entre escritores" (Gusmán, 2000). Este vínculo amistoso es el mismo que unía a Lamborghini, Gusmán, Germán García, Piglia. En cierto modo una relación de amistad, de escritura y también una relación crítica. Afirmo esto porque, para los lectores y también para la crítica de entonces, textos como El fiord, Sebregondi retrocede, o El frasquito eran prácticamente ilegibles. Es entonces que las primeras ediciones llevan prólogos o posfacios a cargo del núcleo de amigos que ofician como modos (o instrucciones) de lectura. Una alianza provisoria para enfrentar las convicciones lectoras dominantes y poco comprensivas de un nuevo código escriturario. Recordemos: Germán García escribe (con seudónimo: Leopoldo Fernández) el posfacio a El fiord ("Los nombres de la negación"), Ricardo Piglia el prólogo a El frasquito ("El relato fuera de la ley”).

FIGURA 2

Elfiord dedicado por el autor

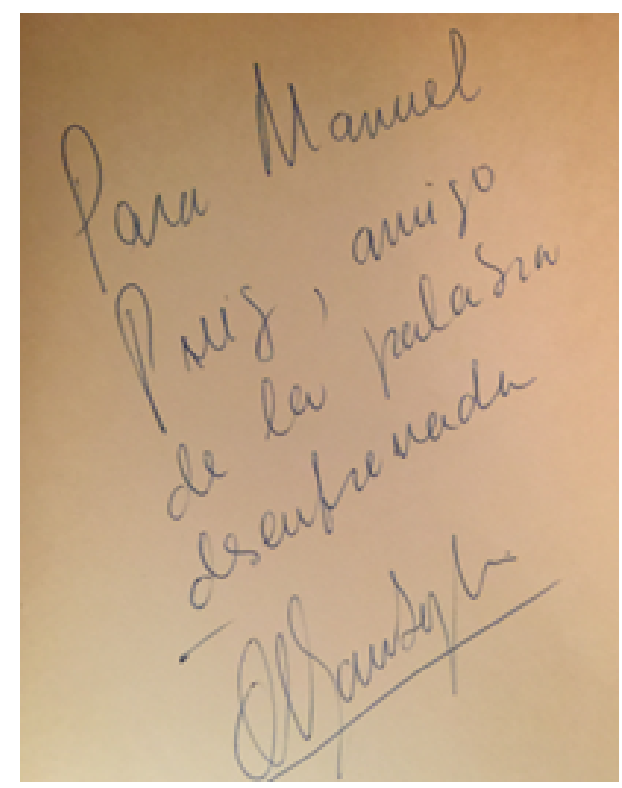

(Biblioteca Manuel Puig) 
FIGURA 3

La pérdida del reino dedicado por el autor

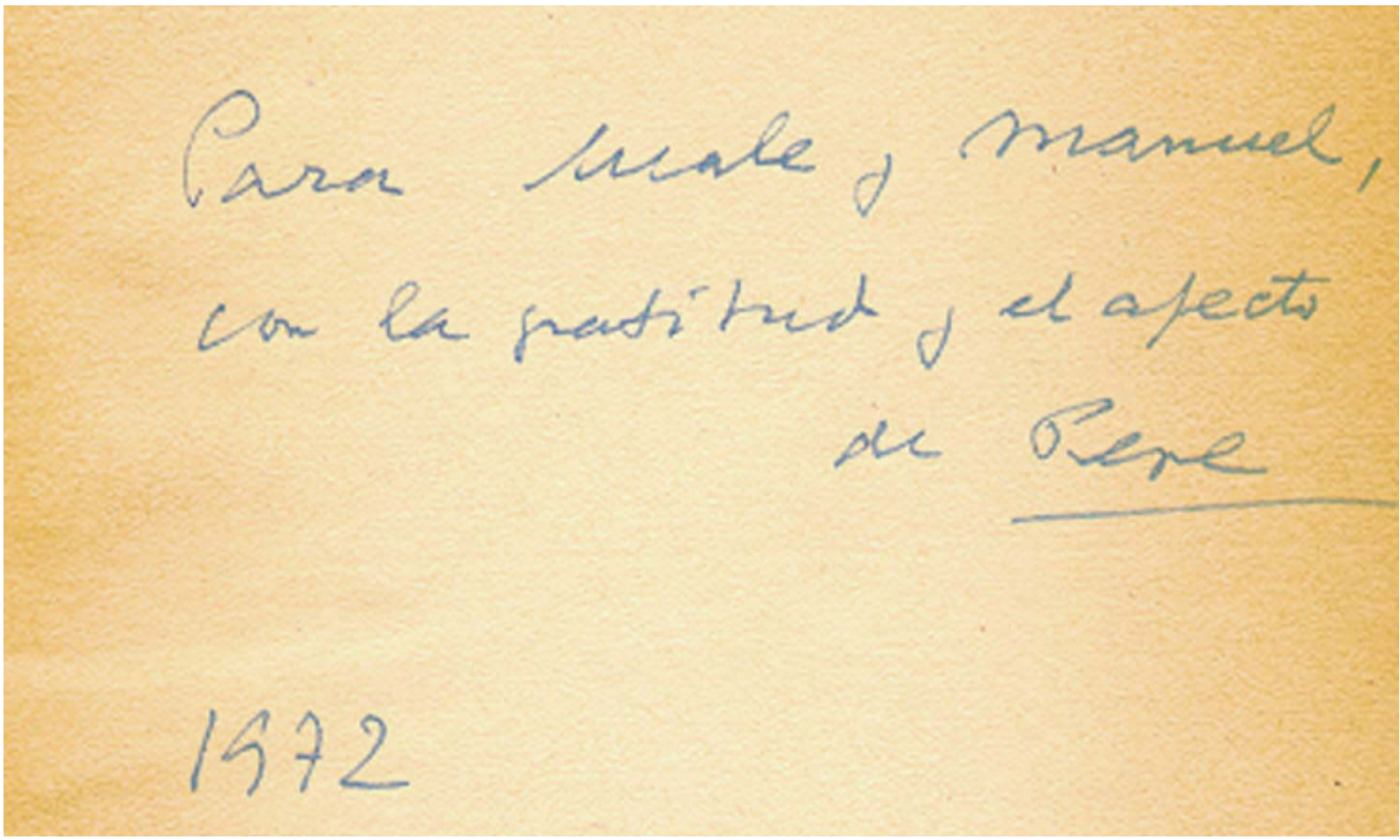

(Biblioteca Manuel Puig)

FIGURA 4

Cuerpo velado dedicado por el autor

LUIS GUSMAN

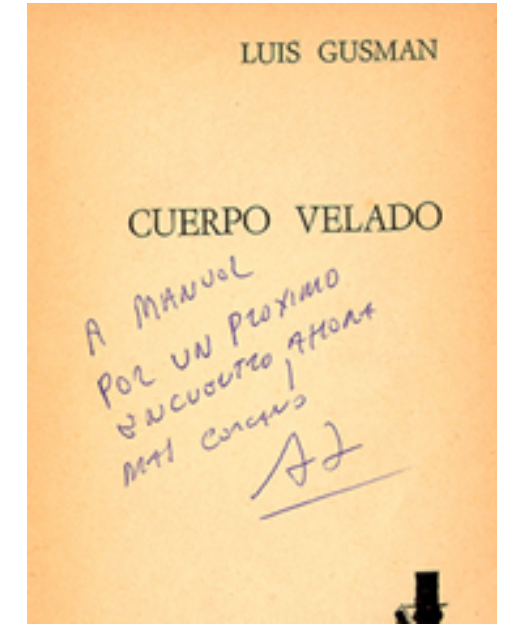

(Biblioteca Manuel Puig)

Asediados por la censura del onganiato estos textos muestran la profunda relación que tienen con el arenal político argentino. Por mi parte, y en relación con esa falta de libertad de pensamiento, había olvidado un pequeño detalle del artículo que publiqué en la Revista Iberoamericana y que me devuelve toda la pasada ignominia de aquellos años (1983: finales de la dictadura militar). Como es de uso en una publicación académica, debajo del título de la colaboración y del nombre de su autor se consigna la universidad a la que pertenece, y en mi caso se lee "Universidad del Salvador, Buenos Aires". Para algunos intelectuales de entonces esta universidad significó una especie de refugio intelectual o de exilio durante los años de plomo. Yo trabajé allí con Jorge Lafforgue (los dos enseñábamos Literatura Latinoamericana) y con el latinista Eduardo Prieto. 
Mi colaboración en la Revista Iberoamericana, en un número dedicado a la literatura argentina, se debe también a la confianza de una amiga, a Sylvia Molloy que recopiló esa entrega. Me complace haber estado rodeado de tantas miradas y complicidades amigas en esos momentos primeros.

Seguramente ese balbuceo crítico que trataba, sin saberlo, de dar cuenta de lo que en la jerga crítica se llama “imagen de autor", y que es en realidad el diálogo con un fantasma alrededor de lo escrito, pero también la mitología construida alrededor de un nombre, y de las anécdotas que lo sostienen, parodian o degradan. Hoy tengo la ilusión, no solo de haber dialogado con ese fantasma surgido de las conversaciones con amigos, sino también de haber hecho honor a una amistad que no tiene precio, y, por lo tanto, queda suspendida en otras ilusiones que la letra sostiene.

\section{REFERENCIAS}

Bronckart, J. P y Bota, C. (2013 [2011]). Bajtín desenmascarado. Historia de un mentiroso, una estafa y un delirio colectivo. Madrid, España: Machado.

Gusmán, L. (2020). Manuel Puig, el más contemporáneo de todos. Revista Ñ. Recuperado de https://www.clarin.co $\mathrm{m} /$ revista-enie/literatura/manuel-puig-contemporaneo_0_rB94P8AwW.html

Ludmer, J. (1971). Boquitas pintadas, siete recorridos. Actual. Revista de la Universidad de los Andes, II (8-9).

Panesi, J. (1983). Manuel Puig: las relaciones peligrosas. Revista iberoamericana, XLIX (125), 903-916.

Piglia, R. (2019). Teoría de la prosa. Buenos Aires, Argentina: Eterna Cadencia.

Piglia, R. (1972 [1969]). Clase media: cuerpo y destino (Una lectura de La traición de Rita Hayworth de Manuel Puig) En Nueva novela latinoamericana 2. Buenos Aires, Argentina: Paidós.

Tiniavov, I. (2016). Sobre la evolución literaria. En T. Todorov (comp.) Teoría de la literatura de los formalistas rusos. Buenos Aires, Argentina: Siglo XXI. 